\title{
Trichomonas vaginalis as a risk factor for human papillomavirus: a study with women undergoing cervical cancer screening in a northeast region of Brazil
}

Ilka Kassandra Pereira Belfort ${ }^{1 *}$ (C), Ana Paula Almeida Cunha ${ }^{2}$, Francisco Pedro Belfort Mendes ${ }^{2}$, Leonardo Victor Galvão-Moreira ${ }^{3}$, Renata Gaspar Lemos ${ }^{4}$, Lucas Henrique de Lima Costa ${ }^{4}$, Pablo Monteiro ${ }^{4}$, Mariele Borges Ferreira ${ }^{4}$, Gerusinete Rodrigues Bastos dos Santos ${ }^{2}$, Joyce Leal Costa ${ }^{2}$, Alice de Sá Ferreira ${ }^{2}$, Luiz Gustavo Oliveira Brito ${ }^{5}$, Luciane Maria Oliveira Brito², Flávia Castello Branco Vidal ${ }^{2}$ and Sally Cristina Moutinho Monteiro ${ }^{2,4}$

\begin{abstract}
Background: Human papillomavirus (HPV) and Trichomonas vaginalis (TV) infections are the most common sexually transmitted infections (STIs) globally. The latter has contributed to a variety of adverse outcomes for both sexes. Moreover, in Brazil, epidemiological studies on patients with STIs are limited. Therefore, this study aimed to determine the prevalence of TV and its association with HPV in women undergoing cervical cancer screening.

Methods: Women with a normal cervix were recruited from a community-based cervical cancer screening program. Gynecological examinations were conducted, and questionnaires were provided. Vaginal canal and uterine cervix samples were collected for cytological examinations (reported using the 2001 Bethesda System) and tested for the presence of TV and HPV DNA.

Results: In total, 562 women who attended public primary healthcare were included in the study. The T. vaginalis was present in 19.0\% (107) and HPV DNA was present in 46.8\% (263) of women. Among the women of TV 73.8\% (79) had a co-infection with HPV $(p=0.001)$.

Conclusions: We concluded that a TV infection is associated with an HPV infection of the cervix as well as with the cervical cytological abnormalities. Further studies could reveal the mechanisms by which these two organisms interact at the cellular level, with control for shared behavioral risk factors.
\end{abstract}

Keywords: Sexually transmitted infection, Trichomonas vaginalis, Human papillomavirus, Co-infection

*Correspondence: ilkabelfort@gmail.com

${ }^{1}$ Doctoral Program in Biotechnology - Northeast Biotechnology Network (RENORBIO), Federal University of Maranhão (UFMA), Rua 4 Quadra 9 Casa

3 Residencial Primavera, São Luis, MA 65052-850, Brazil

Full list of author information is available at the end of the article

\section{Background}

Sexually transmitted infections (STIs) represent a significant public issue that affects people`s health worldwide. [1]. In 2016, an estimation of 376 million new infections (more than 1 million per day) was reported in people aged between 15 and 49 years [2]. Trichomonas vaginalis (TV) and Human Papillomavirus (HPV) infections are among the most common STIs; 
however, the prevalence of these STIs varies significantly globally, with a higher prevalence in countries with low socioeconomic indexes [3].

These infections can lead to multiple complications, especially in women, including urogenital-related issues (cervicitis, urethritis, vaginitis, and genital ulceration), complications during pregnancy, infertility, increased risk of acquisition and transmission of human immunodeficiency virus, and cancer [3-5].

HPV is associated with several types of cancer, including cervical and penile cancer [6]. The incidence of cervical cancer is higher than 528,000 cases per year, with more than 270,000 deaths caused by it [1]. The global prevalence of HPV in women with normal cytology is estimated at $11.7 \%$ but can reach up to $55.4 \%$ in Brazil $[1,7]$.

Persistent infection by viral types of high oncogenic risk, mainly by HPV types 16 and 18, is one of the main factors for the development of cervical cancer. Many co-factors contribute to the persistent HPV infection and the progression of cervical lesions, including biological, behavioral, and environmental factors, as well as other sexually transmitted infections (STIs) [8].

Sexually transmitted infections may play a crucial role in HPV persistence, leading to serious complications, since it facilitates HPV entry (single or multiple viruses) and decreases the host's ability to resolve the viral infection. Moreover, the chronic inflammation caused by STI and HPV can act as a promoter of carcinogenesis by inducing the occurrence of significant cellular and molecular changes [9-11].

Trichomonas vaginalis (TV) is a flagellated, facultatively anaerobic protozoan of the human genital tract [12]. It is the most common, non-viral, sexually transmitted agent worldwide, responsible for 143 million cases in 2012 and 110.4 million in 2018 [2]. Epidemiological studies have shown that TV infection can lead to an increased risk of cervical cancer [13-16]. The interaction between cervical cancer and TV is not yet fully elucidated, but it is believed that the inflammatory process caused by this protozoan predisposes the epithelium to carcinogenesis [12, 17-19]. Cervical epithelium disruption is due to the inflammation process caused by TV, which facilitates the entry of HPV into the basal layer of the epithelium. As a result, it leads to the integration of viral DNA into the host DNA and the overexpression of viral oncogenes that contribute to the activation of carcinogenic mechanisms [17, 19, 20].

In this perspective, the study goal was to determine the prevalence of TV and its association with HPV in women who sought to undergo cervical cancer screening in Northeastern Brazil.

\section{Methods}

\section{Study population}

This cross-sectional and non-interventional study was conducted with 562 women who were patients at the public health units of gynecological care in São Luís, Maranhão, Brazil. The sample size was calculated considering a prevalence of $11.2 \%$ of women with TV [2], a power of $90 \%$ and a $5 \%$ significance level. The calculated sample was 384 women; however, 562 women were included in the study.

The study was approved by the Ethics Committee on Human Research (Federal University of Maranhão - protocol number 2.383.604) and all the potential women were counselled by the investigators about the objectives and methodology of the study. Was obtained written informed consent from all participants. Consent forms were kept separately from questionnaires and biological samples so names could not be linked to any study data collected.

Sociodemographic and clinical data were obtained by semi structured questionnaire based on validated instruments (age, ethnicity, education, family income, professional activity, marital status, sexual behavior, alcohol consumption, smoking status, and reproductive health and barrier methods used). The following exclusion criteria were applied: women who were menstruating, underwent hysterectomy, were virgins, or pregnant for less than 45 days postpartum.

\section{Cervical cytology}

Ayre's spatula was used to obtain cervical scraping, fixed on a glass slide with ethanol, and stained using for Pap smear. Cytological examinations of Pap smear were reported using the 2001 Bethesda Reporting System.

\section{Specimen collection and DNA extraction}

For HPV DNA isolation, samples were obtained using a Digene HC2 DNA Collection Device (QIAGEN, CA, USA) and stored at $-20{ }^{\circ} \mathrm{C}$ until processed. DNA extraction was done using the QIAamp DNA Mini and Blood kit (QIAGEN, CA, USA), according to the manufacturer instructions. DNA extraction was confirmed by amplification of the $\beta$-globin gene. Total DNA was isolated, eluted in $100 \mathrm{~mL} \mathrm{AE}$ buffer, and stored at $-20{ }^{\circ} \mathrm{C}$.

\section{HPV and TV detection}

The presence of HPV DNA was detected using nested polymerase chain reaction (PCR) with the primer sets PGMY09/11 (first round of PCR) and GP+5/GP+6 (second round of PCR) [21]. Presence of TV was 
detected using conventional PCR with the primers TVA5/6 [22].

Amplification products were evaluated using electrophoresis with a $1.5 \%$ agarose gel in $1 \times \mathrm{TBE}$ buffer for 30 minutes at $5 \mathrm{~V} / \mathrm{cm}$ in a horizontal unit (Life Technologies, Carlsbad, CA, USA). Bands were stained with $0.1 \%$ Gel Red (Invitrogen) and visualized using an ultraviolet transilluminator (BioRad Laboratories, Hercules, CA, USA).

\section{HPV Genotyping}

PCR products were typed by Big Dye Terminator v3.1 Cycle Sequencing Kit (Applied Biosystems, Foster City, CA), and analyzed using an ABI Prism 3130XL Genetic Analyzer (Applied Biosystems). The sequences were edited and analyzed using 4Peaks Software (Nucleobytes, Amsterdam, Netherlands). HPV genotypes were identified using the BLASTn (Basic Local Alignment Search Tool, http://blast.ncbi.nlm.nih.gov/).

\section{Data analysis}

Statistical analyses were performed using the IBM SPSS ${ }^{\circledR}$ software version 23. Initial descriptive analyses were performed to assess the categorical variables, and the chi-square test was performed for comparison between groups. The results were considered statically significant when $p \leq 0.05$. After a univariate analysis performed by the chi-square test, variables with a significance level $\leq$ of 0.05 were selected to assess their independent contribution to the onset of trichomoniasis infection through a multivariate analysis using binary logistic regression. In addition, a ROC (Receiver Operating Characteristic) curve was performed to verify the quality of the prediction of the final regression model.

\section{Results}

In total, 562 women who attended public primary healthcare from June 2017 to July 2019 were included in the study. Trichomonas vaginalis was present in 19.0\% (107), and HPV DNA was present in 46.8\% (263) of women. Among women of TV, 73.8\% (79) had a co-infection with $\operatorname{HPV}(p=0.001)$.

Women aged between 30 and 49 years $(48.40 \%)$, selfdeclared non-white color (90.04\%), no having a fixed partner (52.49\%), and women with high-school level education $(52.49 \%)$ were predominant. Regarding risk factors and sexual habits, most women reported nonsmokers (90.39\%), non-alcoholics (62.10\%), not using condoms during sexual intercourse (77.05\%), having anal (67.97\%) and oral sex (95.55\%), and absence of previous STI (60.85\%).

The results of cytology testing reported that 48 (8.5\%) women had cervical abnormalities, which included 16
(2.8\%) classified as ASCUS (Atypical Squamous Cells of Unknown Significance), 6 (1.1\%) classified as ASCH (Atypical Squamous Cells of Indeterminate Significance), 16 (2.8\%) classified as LGSIL (Low-Grade Squamous Intraepithelial Lesion), 4 (0.7\%) classified as HGSIL (High-grade squamous intraepithelial lesion), and 6 (1.1\%) classified CIN II + CIN III (Cervical Intraepithelial Neoplasia) (Table 1).

Infection with TV was associated with skin color $(p=$ $0.042)$, not using condoms $(p=0.016)$, age of menarche $(p=0.004)$, presence of cytological abnormalities $(p=$ $0.001)$, and HPV infection $(p<0.001)$ (Table 1$)$.

The univariate analysis reported statistically significant results $(p<0.05)$ among the variables color, no condom use, cytological alteration, HPV infection, and menarche. Thus, we performed a binary logistic regression model to verify the prediction of these explanatory variables regarding the acquisition of Trichomonas vaginalis infection.

The final regression model was constructed using all the significant variables from the univariate analysis in block 1 . The variables that showed $p \leq 0.2$ were included in block 2 (menarche, no condom use, cytological alteration, and HPV infection). All these variables showed $p$ $\leq 0.05$ by Wald's statistics, so they remained in the final model.

Binary logistic regression showed that menarche remained associated with TV infection, and women who had menarche after 13 years of age are 2111 more likely to contract TV.

Similarly, HPV is also associated with trichomoniasis in a multivariate analysis, showing that HPV infection increases by 2297 a chance of developing TV infection.

On the other hand, the use of condoms is a protective factor against the non-development of $\mathrm{TV}$, corroborating the univariate analysis, where the non-use of condoms resulted in a relationship with TV. Thus, the use of condoms decreases by 0.577 times the chance of acquiring TV infection.

Also, when verifying the association between cytological alteration and TV, the binary logistic regression model showed that women who had LGSIL and ASCH infection have 3179 and 12047 more chances of having TV infection, respectively. Table 2 shows the multivariate analysis using binary logistic regression.

We used the ROC curve (Receiver Operating Characteristic) to verify the fit quality of the final model regarding the discriminatory power of TV infection. The area under the curve showed a value of 0.746 , considered a good discrimination power (Fig. 1).

HPV genotyping was performed in 263 samples, of which showed that $85(32.3 \%)$ of cervical samples were classified as high risk, 40 (15.2\%) were classified as low 
Table 1. Demographic, sexual habits and clinical data of woman treated in public health care, São Luís, Maranhão, Brazil

\begin{tabular}{|c|c|c|c|c|c|c|c|}
\hline & \multirow{2}{*}{\multicolumn{2}{|c|}{ Total $(\mathrm{N}=562)$}} & \multicolumn{4}{|c|}{ Trichomonas vaginalis } & \multirow[t]{3}{*}{$p$ value } \\
\hline & & & \multicolumn{2}{|c|}{ Yes $(N=107)$} & \multicolumn{2}{|c|}{ No $(N=455)$} & \\
\hline & $\mathrm{N}$ & $\%$ & $\mathrm{~N}$ & $\%$ & $\mathrm{~N}$ & $\%$ & \\
\hline \multicolumn{8}{|l|}{ Age } \\
\hline$<29$ years & 155 & 27.58 & 30 & 19.35 & 125 & 80.65 & 0.473 \\
\hline 30-49 years & 272 & 48.40 & 56 & 20.59 & 216 & 79.41 & \\
\hline $50+$ years & 135 & 24.02 & 21 & 15.56 & 114 & 84.44 & \\
\hline \multicolumn{8}{|l|}{ Skin color } \\
\hline White & 56 & 9.96 & 5 & 8.93 & 51 & 91.07 & 0.042 \\
\hline Non-white & 506 & 90.04 & 102 & 20.16 & 404 & 79.84 & \\
\hline \multicolumn{8}{|l|}{ Relationship status } \\
\hline With partner & 267 & 47.51 & 51 & 19.10 & 216 & 80.90 & 0.972 \\
\hline Single & 295 & 52.49 & 56 & 18.98 & 239 & 81.02 & \\
\hline \multicolumn{8}{|l|}{ Education level } \\
\hline Elementary school & 196 & 34.88 & 41 & 20.92 & 155 & 79.08 & 0.707 \\
\hline High-school level & 295 & 52.49 & 53 & 17.97 & 242 & 82.03 & \\
\hline Graduate school & 71 & 12.63 & 13 & 18.31 & 58 & 81.69 & \\
\hline \multicolumn{8}{|l|}{ Smoking status } \\
\hline No & 508 & 90.39 & 95 & 18.70 & 413 & 81.30 & 0.531 \\
\hline Yes & 54 & 9.61 & 12 & 22.22 & 42 & 77.78 & \\
\hline \multicolumn{8}{|l|}{ Alcohol consumption } \\
\hline No & 349 & 62.10 & 65 & 18.62 & 284 & 81.38 & 0.749 \\
\hline Yes & 213 & 37.90 & 42 & 19.72 & 171 & 80.28 & \\
\hline \multicolumn{8}{|l|}{ Condom use } \\
\hline No & 433 & 77.05 & 73 & 16.86 & 360 & 83.14 & 0.016 \\
\hline Yes & 129 & 22.95 & 34 & 26.36 & 95 & 73.64 & \\
\hline \multicolumn{8}{|l|}{ Menarche } \\
\hline Before 13 years old & 342 & 60.9 & 52 & 48.6 & 290 & 63.7 & 0.004 \\
\hline After 13 years old & 220 & 39.1 & 55 & 51.4 & 165 & 36.3 & \\
\hline \multicolumn{8}{|l|}{ Anal sex } \\
\hline No & 180 & 32.03 & 38 & 21.11 & 142 & 78.89 & 0.390 \\
\hline Yes & 382 & 67.97 & 69 & 18.06 & 313 & 81.94 & \\
\hline \multicolumn{8}{|l|}{ Oralsex } \\
\hline No & 25 & 4.45 & 3 & 12.00 & 22 & 88.00 & 0.359 \\
\hline Yes & 537 & 95.55 & 104 & 19.37 & 433 & 80.63 & \\
\hline \multicolumn{8}{|c|}{ Cytological abnormality } \\
\hline No & 514 & 91.5 & 86 & 80.4 & 428 & 94.1 & 0.001 \\
\hline ASC-US & 16 & 2.8 & 6 & 5.6 & 10 & 2.2 & \\
\hline LGSIL & 16 & 2.8 & 8 & 7.5 & 8 & 1.8 & \\
\hline $\mathrm{ASC}-\mathrm{H}$ & 6 & 1.1 & 4 & 3.7 & 2 & 0.4 & \\
\hline HGSIL & 4 & 0.7 & 3 & 2.8 & 1 & 0.2 & \\
\hline CIN $\|+C I N\| I$ & 6 & 1.1 & 0 & 0 & 6 & 1.3 & \\
\hline \multicolumn{8}{|l|}{$H P V$} \\
\hline No & 299 & 53.2 & 28 & 26.2 & 271 & 59.6 & 0.001 \\
\hline Yes & 263 & 46.8 & 79 & 73.8 & 184 & 40.4 & \\
\hline
\end{tabular}

Bold values indicate the results were considered statically significant when $p \leq 0.05$

ASCUS atypical squamous cells of unknown significance, ASCH atypical squamous cells of indeterminate significance, LGSIL Low-Grade Squamous Intraepithelial Lesion, HGSIL high-grade squamous intraepithelial lesion, CIN II cervical intraepithelial neoplasia II, CIN cervical intraepithelial neoplasia III 
Table 2. Multivariate analysis using binary logistic regression for the infection of Trichomonas vaginalis of woman treated in public health care, São Luís, Maranhão, Brazil

\begin{tabular}{llll}
\hline & \multicolumn{2}{l}{ Trichomonas vaginalis } & \multirow{2}{*}{$\boldsymbol{p}$ value } \\
\cline { 2 - 3 } & \multicolumn{1}{c}{ Odds ratio-IC (95\%) } & Wald & \\
\hline Menarche & & & \\
Before 13 years old & Ref & & \\
After 13 years old & $2.111(1.328-3.356)$ & 9.987 & $\mathbf{0 . 0 0 2}$ \\
Use condon & & & \\
Yes & $0.577(0.348-0.956)$ & 4.548 & $\mathbf{0 . 0 3 3}$ \\
No & Ref & & \\
HPV & & & \\
Yes & $2.297(1.461-3.610)$ & 12.993 & $\mathbf{0 . 0 0 1}$ \\
No & Ref & & \\
Color & & & \\
White & Ref & & \\
Nonwhite & $2.216(0.844-5.815)$ & 2.613 & 0.106 \\
Cytological abnormality & & & \\
No & Ref & - & - \\
ASC-US & $2.659(0.878-8.052)$ & 2.993 & 0.084 \\
LGSIL & $3.179(1.099-9.201)$ & 4.552 & $\mathbf{0 . 0 3 3}$ \\
ASC-H & $12.047(1.986-73.069)$ & 7.323 & $\mathbf{0 . 0 0 7}$ \\
HGSIL & $8.167(0.815-81.872)$ & 3.189 & 0.074 \\
CIN II + CIN III & 0 & 0 & 0 \\
\hline Bold values indicte the & & \\
\hline
\end{tabular}

Bold values indicate the results were considered statically significant when $p \leq$ 0.05

ASCUS atypical squamous cells of unknown significance, $A S C H$ atypical squamous cells of indeterminate significance, LGSIL low-grade squamous intraepithelial lesion, HGSIL high-grade squamous intraepithelial lesion, CIN II cervical intraepithelial neoplasia II, CIN cervical intraepithelial neoplasia III

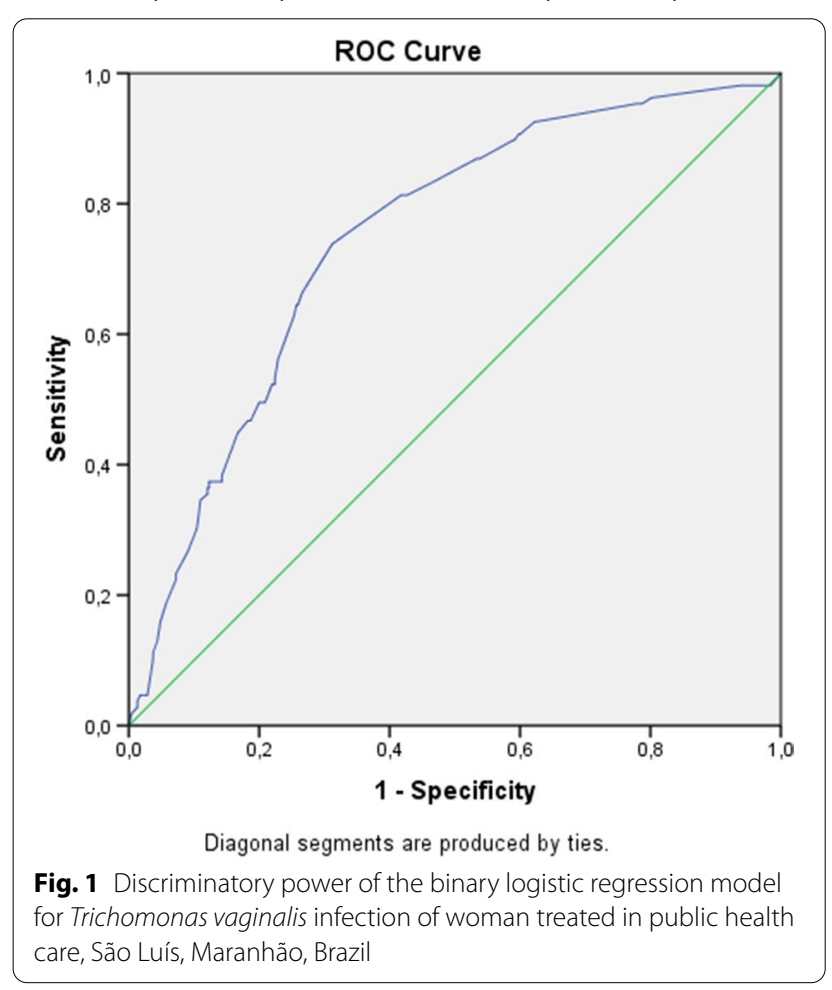

risk and 138 (52.4\%) samples were classified as indeterminate (low or high risk). We performed a binary logistic regression to evaluate the relationship between HPV viral types and TV infection. However, the 138 undetermined genotypes were excluded from the analysis, as it would behave as a possible confounding factor in the analysis.

In the regression analysis, no association between the specific kinds of HPV and TV was found, and it was possible to verify that not having HPV infection decreases the chance of having TV by 0.272 times. Data presented in Table 3.

\section{Discussion}

HPV and TV infections are among the most common STIs worldwide, both associated with multiple health consequences in men and women [12]. TV infection can lead to an increased risk of cervical cancer [13-16]. The interaction between cervical cancer and TV is not yet fully elucidated, but it is believed that the inflammatory process caused by this protozoan predisposes the epithelium to carcinogenesis [12, 17-19].

Studies have shown that a previous history of infection with TV leads to an increased risk of HPV infection, mainly owing to the viral types of high oncogenic risk $[13,18,23]$. HPV is considered the etiological factor of cervical cancer; however, the fact that some women manage to eliminate HPV without the development of cervical lesions leads to the question that other cofactors can facilitate the persistence of this virus, thereby preventing its elimination and favoring cervical changes mediated by HPV [18].

In this context, the present study affirmed the association of TV with HPV. It was thus demonstrated that HPV is a risk factor for $\mathrm{TV}$, suggesting that there is a possible cooperation between both microorganisms, contributing to cellular microenvironment changes.

TV releases lytic enzymes that reduce the protective mucus layer of the vaginal wall, leading to a reduction in vaginal fluids [13]. This can lead to the development of micro lesions in the epithelium, thereby increasing virulence the HPV and allowing the integration of the DNA into the host cell, which can lead to host cell DNA

Table 3. Multivariate analysis using binary logistic regression for the development of Trichomonas vaginalis in woman treated in public health care, São Luís, Maranhão, regarding HPV genotyping

\begin{tabular}{llcc}
\hline & Odds ratio-IC (95\%) & Wald & $\boldsymbol{p}$ value \\
\hline HPV & & & \\
Negative & $0.272(0.159-0.466)$ & 22.399 & $\mathbf{0 . 0 0 0}$ \\
High risk & $1.096(0.603-1.993)$ & 0.091 & 0.763 \\
Low risk & $1.754(0.842-3.657)$ & 2.249 & 0.134 \\
\hline
\end{tabular}

Bold value indicate the results were considered statically significant when $p \leq$ 0.05 
damage and the beginning of the carcinogenic process [12]. The inflammatory process can also rupture the basal layer of the cervical epithelium and thus facilitate its persistence in the cervical-vaginal epithelium tissue $[12,19]$.

In this context, it is important to evaluate the influence of TV and HPV co-infection in the genital tract of women without cervical cancer to understand these cofactors. However, the differences in prevalence are observed globally, with $1.9 \%$ in Busan/South Korea [24], $3.1 \%$ in Shanghai/China [25], 5.6\% in female sex workers in the Midwest region of Brazil [26], 5.7\% in Bahia/ Brazil [27], 31.4\% in Kenya [28], 18.8\% in Beijing/China [29], and $24 \%$ in the rural area of Ngaramtoni /Tanzania [13]. The results presented here demonstrate a $27 \%$ coinfection prevalence of TV and HPV, which is in line with the studies mentioned above.

In addition to HPV infection, multivariate analysis showed that other cofactors were also associated with TV infection in the study population, such as cytological abnormality and inconsistent condom use. Studies have found an association between TV infection, cervicitis, and vaginal infections in the increased risk of squamous intraepithelial lesions and/or cervical intraepithelial neoplasia (CIN) [28-30], mainly associated with persistent HPV infection [25, 30-32].

The mechanism associated with cervical dysplasia and persistent HPV infection in the context of cohabitating STIs is the alterations caused by the inflammation of the cervical epithelium. When the inflammatory process induced by the STI disrupt the epithelium, high-risk HPV (HR HPV) can penetrate to the basal layer and alter multiple cell activity $[17,19,20,31,32]$.

Individuals who do not use condoms are at higher risk of infection and reinfection by HPV and other STIs, which also contribute to cervical lesions progression [33, $34]$, probably leading to the chronic local inflammatory process and intensified immune system stimulation [12, $19,35]$. In contrast, the constant use of condoms is associated with a lower risk of HPV infection and regression of cervical lesions rates, as it allows the immune system to act and repair the damaged tissue, preventing the progression of the lesion. [36].

The analysis of HPV genotyping demonstrated that no association between the specific kinds of HPV and TV was found, though these data must be analyzed with care, since the number of HPV indeterminates was high. In addition, it was possible to verify that not having HPV infection decreases the chance of having TV by 0.272 times, which strengthened the hypothesis of a possible cooperation between both microorganisms, contributing to cellular microenvironment changes.

This study confirms the correlation between TV and HPV among women who sought to undergo cancer screening. Since the participants were evaluated in a cross-sectional study design, we could not identify the causal relationship between these infectious agents. Although physiologically plausible, the mechanism(s) by which an association between TV infection, cervicitis, and vaginal infections in the increased risk of squamous intraepithelial lesions and/or cervical intraepithelial neoplasia a prospective cohort study would be adequate to assess the linkage between TV/HPV coinfections and the development of precursor cancer lesions.

\section{Conclusion}

TV infection was associated with HPV infection of the cervix as well as with cervical cytological abnormalities. The scale and prevalence of co-infections in our study population justify the necessity of attention by public health services and demonstrate the importance of condoms and the frequency in which female sex workers undergo oncotic cytology examinations. Further studies could reveal the mechanisms by which these two organisms interact at the cellular level and how these shared behavioral risks act for the progression of precancer cervical lesions.

\section{Abbreviations}

AIR: Australian Immunization Register; CEP-UFMA: Research Ethics Committee of the Federal University of Maranhão; DNA: deoxyribonucleic acid; ESF: family health strategy; USA: United States of America; HIV: human immunodeficiency virus; HPV: human papillomavirus; IARC: International Cancer Research Agency; STI: sexually transmitted infection; MS: Ministry of Health; WHO: World Health Organization; PCR: polymerase chain reaction; SUS: unified health system; FICF: informed consent form; UBS: basic health units; TV: Trichomonas vaginalis; WHO: World Health Organization.

\section{Acknowledgements \\ We are grateful to all the women who agreed to participate in this research and for having shared a little of their history with us.}

\section{Authors' contributions}

IKPB — research design, sampling collections, analyzed and interpreted the data and was a contributor in writing the manuscript. APAC - sampling collections, analyzed and interpreted the data and was a contributor in writing the manuscript. FPBM — sampling collections, analyzed and interpreted the data. LVM - Statistics, analyzed and interpreted the data. RGL-sampling collections and analyzed and interpreted the data. LHLC — sampling collections and analyzed the data. PM — sampling collections and analyzed data. MBF_-sampling collections and analyzed data. GRBS - performed the citological examination of lamines. JLC - sampling collections, analyzed and interpreted the data. ASF_-statistic and analyzed data. LGOB_-reading and correcting the manuscript. LMOB-reading and correcting the manuscript. FCBV-contributor in writing the manuscript. SCMM — research design, analyzed and interpreted patients' data and contributed in writing the manuscript. All authors read and approved the final manuscript.

\section{Funding}

To Fundação de Amparo à Pesquisa e ao Desenvolvimento Científico e Tecnológico do Maranhão (FAPEMA) for the partial support in this research (specimen collection and molecular determination of the human papillomavirus were made with materials from research). The Biobanco de Tumores e DNA do Maranhão (BTMA) provited the physical space and equipment. 


\section{Availability of data and materials}

The datasets used and/or analysed during the current study are available from the corresponding author on reasonable request.

\section{Declarations}

\section{Ethical Approval and Consent to participate}

The study was approved by the Ethics Committee on Human Research (Federal University of Maranhão - protocol number 2.383.604) and all the potential women were counselled by the investigators about the objectives and methodology of the study. Was obtained written informed consent from all participants. Consent forms were kept separately from questionnaires and biological samples so names could not be linked to any study data collected.

\section{Consent for publication}

Not applicable.

\section{Competing interests}

There are no conflicts of interest.

\section{Author details}

'Doctoral Program in Biotechnology - Northeast Biotechnology Network (RENORBIO), Federal University of Maranhão (UFMA), Rua 4 Quadra 9 Casa 3 Residencial Primavera, São Luis, MA 65052-850, Brazil. ${ }^{2}$ Postgraduate Program in Adult Health, Federal University of Maranhão, São Luís, MA, Brazil. ${ }^{3}$ Federal University of Maranhão (UFMA), São Luís, MA, Brazil. ${ }^{4}$ Department of Pharmacy, Federal University of Maranhão (UFMA), São Luís, MA, Brazil. ${ }^{5}$ Department of Tocogynecology (DTG), Faculty of Medical Sciences (FCM), State University of Campinas (UNICAMP), Campinas, Brazil.

Received: 28 August 2020 Accepted: 19 April 2021

Published online: 23 April 2021

\section{Reference}

1. Serrano B, Brotons M, Bosch FX, Bruni L. Epidemiology and burden of HPV-related disease. Best Pract Res Clin Obstet Gynaecol. 2018;47:14-26. https://doi.org/10.1016/j.bpobgyn.2017.08.006.

2. World Health Organization. Report on global sexually transmitted infection surveillance 2018 [Internet]. 2018 [cited 2019 June 19]; Available from: https://apps.who.int/iris/bitstream/handle/10665/277258/97892 41565691-eng.pdf?ua=1.

3. Rowley J, Hoorn SV, Korenromp E, Low N, Unemo M, Abu-Raddad LJ, et al. Chlamydia, gonorrhoea, trichomoniasis and syphilis: global prevalence and incidence estimates, 2016. Bull World Health Organ. 2019:97:548-62. https://doi.org/10.2471/BLT.18.228486.

4. Holmes KK, Sparling PF, Stamm WE, Piot P, Wasserheit JN, Corey L, et al. Sexually transmitted diseases. 4th ed. New York: McGraw-Hill Medical; 2008.

5. Torrone EA, Morrison CS, Chen P-L, Kwok C, Francis SC, Hayes RJ, et al. Prevalence of sexually transmitted infections and bacterial vaginosis among women in sub-Saharan Africa: an individual participant data meta-analysis of $18 \mathrm{HIV}$ prevention studies. PLoS Med. 2018;15(2):1002511. https://doi.org/10.1371/journal.pmed.1002511.

6. Schiffman M, et al. Carcinogenic human papillomavirus infection. Nat Rev Dis Primers. 2016:2:16086. https://doi.org/10.1038/nrdp.2016.86.

7. Wendland EM, Doorbar J, Wentzensen N, de Sanjosé S, Fakhry C, Monk BJ, et al. POP-Brazil study protocol: a nationwide cross-sectional evaluation of the prevalence and genotype distribution of human papillomavirus (HPV) in Brazil. BMJ Open. 2018;8(6):1-6. https://doi.org/10.1136/bmjop en-2017-021170.

8. Del Prete R, Ronga L, Magrone R, Addati G. Epidemiological evaluation of human papillomavirus genotypes and their associations in multiple infections. Epidemiol Infect. 2019;147(132):1-9. https://doi.org/10.1017/ S0950268818003539.

9. Gravitt PE, Winer RL. Natural history of HPV infection across the lifespan: role of viral latency. Viruses. 2017:9(10):1-10. https://doi.org/10.3390/ v9100267.
10. De Sanjosé S, Brotons M, Pavón MA. The natural history of human papillomavirus infection. Best Pract Res Clin Obstet Gynaecol. 2018;47:2-13. https://doi.org/10.1016/j.bpobgyn.2017.08.015.

11. Rader JS, Tsaih SW, Fullin D, Murray MW, Iden M, Zimmermann MT, et al. Genetic variations in human papillomavirus and cervical cancer outcomes. Int J Cancer. 2019;10:17-21. https://doi.org/10.1002/ijc.32038.

12. Yang $\mathrm{S}$, Zhao W, Wang H, Wang Y, Li J, Wu X. Trichomonas vaginalis infection-associated risk of cervical cancer: a meta-analysis. Eur J Obstet Gynecol Reprod Biol. 2018;228:166-73. https://doi.org/10.1016/j.ejogrb. 2018.06.031.

13. Lazenby GB, Taylor PT, Badman BS, McHaki E, Korte JE, Soper DE, et al. An Association between Trichomonas vaginalis and high-risk human papillomavirus in rural Tanzanian women undergoing cervical cancer screening. Clin Ther. 2014;36(1):38-45. https://doi.org/10.1016/j.clinthera.2013.11. 009.

14. Ginindza TG, Stefan CD, Tsoka-Gwegweni JM, Dlamini X, Jolly PE, Weiderpass $E$, et al. Prevalence and risk factors associated with sexually transmitted infections (STIS) among women of reproductive age in Swaziland. Infect Agent Cancer. 2017;12:29. https://doi.org/10.1186/ s13027-017-0140-y.

15. Muñoz-Ramírez A, et al. Prevalence of Trichomonas vaginalis and Human papillomavirus in female sex workers in Central Veracruz. Mexico Rev Argent Microbiol. 2018;50(4):351-8. https://doi.org/10.1016/j.ram.2017. 11.004.

16. Kovachev SM. Cervical cancer and vaginal microbiota changes. Arch Microbiol. 2020;202(2):323-7. https://doi.org/10.1007/ s00203-019-01747-4.

17. Castle PE, Giuliano AR. Chapter 4: genital tract infections, cervical inflammation, and antioxidant nutrients- assessing their roles as human papillomavirus cofactors. J Natl Cancer Inst Monogr. 2003;7234(31):29-34. https://doi.org/10.1093/oxfordjournals.jncimonographs.a003478

18. Ghosh I, Muwonge R, Mittal S, Banerjee D, Kundu P, Mandal R, et al. Association between high risk human papillomavirus infection and co-infection with Candida spp. and Trichomonas vaginalis in women with cervical premalignant and malignant lesions. J Clin Virol. 2017;87:43-8. https://doi.org/10.1016/j.jcv.2016.12.007.

19. Mercer F, Johnson PJ. Trichomonas vaginalis: pathogenesis, symbiont Interactions, and Host Cell Immune Responses. Trends Parasitol. 2018;34(8):683-93. https://doi.org/10.1016/j.pt.2018.05.006.

20. Nikas I, Hapfelmeier A, Mollenhauer M, Angermeier D, Bettstetter M, Götz $\mathrm{R}$, et al. Integrated morphologic and molecular analysis of Trichomonas vaginalis, Mycoplasma hominis, and human papillomavirus using cytologic smear preparations. Parasitol Res. 2018;117(5):1443-51. https://doi. org/10.1007/s00436-018-5829-3.

21. Coutlée F, Gravitt P, Kornegay J, Hankins C, Richardson H, Lapointe N, et al. Use of PGMY primers in L1 consensus PCR improves detection of human papillomavirus DNA in genital samples use of PGMY primers in L1 consensus PCR improves detection of human papillomavirus DNA in genital samples. J Clin Microbiol. 2002;40(3):902-7. https://doi.org/10.1128/jcm. 40.3.902-907.2002.

22. Diaz N, Dessì D, Dessole S, Fiori PL, Rappelli P. Rapid detection of coinfections by Trichomonas vaginalis, Mycoplasma hominis, and Ureaplasma urealyticum by a new multiplex polymerase chain reaction. Diagn Microbiol Infect Dis. 2010;67(1):30-6. https://doi.org/10.1016/j.diagmicrobio. 2009.12.022.

23. Donders GGG, Depuydt CE, Bogers JP, Vereecken AJ. Association of Trichomonas vaginalis and cytological abnormalities of the cervix in low risk women. PLoS ONE. 2013;8(12):86266. https://doi.org/10.1371/journal. pone.0086266.

24. Choi SH, Jin H, Lee KE. Prevalence of sexually transmitted pathogen coinfections in high risk-human papillomaviruses infected women in Busan. Biomed Sci Letters 2019; 25:390-397. https://doi.org/10.15616/BSL.2019. 25.4.390

25. Panpan Lv, Zhao F, Xu X, Xu J, Wang Q, Zhao Z Correlation between common lower genital tract microbes and high-risk human papillomavirus infection. Can J Infect Dis Med Microbiol. 2019; 2019: 9678104. https:// doi.org/10.1155/2019/9678104

26. Lugo LZA, Jacob CMB, Machado AP, Almeida FG, Ávila LS, Prata TTM, et al. Human papillomavirus and coinfections with Chlamydia trachomatis, Gardnerella vaginalis, and Trichomonas vaginalis in self-collected samples 
from female sex workers in the Central-Western region of Brazil. J Bras Patol Med Lab. 2018;54:46-51.

27. Amorim AT, Marques LM, Campos GB, Lobão TN, de Souza LV, Cintra $\mathrm{RC}$, et al. Co-infection of sexually transmitted pathogens and human papillomavirus in cervical samples of women of Brazil. BMC Infect Dis. 2017;17(1):769. https://doi.org/10.1186/s12879-017-2835-5.

28. Menon S, Broeck DV, Rossi R, Ogbe E, Harmon S, Mabeya H. Associations between vaginal infections and potential high-risk and high-risk human papillomavirus genotypes in female sex workers in Western Kenya. Clin Ther. 2016;38(12):2567-77. https://doi.org/10.1016/j.clinthera.2016.10. 005.

29. Zhang D, Li T, Chen L, Zhang X, Zhao G, Liu Z. Epidemiological investigation of the relationship between common lower genital tract infections and high-risk human papillomavirus infections among women in Beijing, China. PLoS ONE. 2017;12(5):178033. https://doi.org/10.1371/journal. pone. 0178033

30. Noel JC, Fayt I, Romero Munoz MR, et al. High prevalence of high-risk human papillomavirus infection among women with Trichomonas vaginalis infection on monolayer cytology. Arch Gynecol Obstet. 2010:282:503-5.

31. Watts DH, Fazzari M, Minkoff $H$, et al. Effects of bacterial vaginosis and other genital infections on the natural history of human papillomavirus infection in HIV-1-infected and high-risk HIV-1-uninfected women. J Infect Dis. 2005;191:1129-39.
32. Boyle $\mathrm{DC}$, Barton $\mathrm{SE}$, Uthayakumar $\mathrm{S}$, et al. Is bacterial vaginosis associated with cervical intraepithelial neoplasia? Int J Gynecol Cancer. 2003;13:159-63.

33. Santos Filho MVC, Gurgel AP, Lobo CD, Freitas AC, Silva-Neto JC, Silva $L A$, et al. Prevalence of human papillomavirus (HPV), distribution of HPV types, and risk factors for infection in HPV-positive women. Genet Mol Res. 2016;15(2):1-9. https://doi.org/10.4238/gmr.15028315.

34. Moscicki AB, Schiffman M, Burchell A, Albero G, Giuliano AR, Goodman $M T$, et al. Updating the natural history of HPV and anogenital cancer. Vaccine. 2006;24:42-51. https://doi.org/10.1016/j.vaccine.2012.05.089.

35. Hammes LS, Tekmal RR, Naud P, Edelweiss MI, Kirma N, Valente PT, et al. Macrophages, inflammation and risk of cervical intraepithelial neoplasia (CIN) progression clinicopathological correlation. Gynecol Oncol. 2007;105(1):157-65. https://doi.org/10.1016/j.ygyno.2006.11.023.

36. Skorstengaard M, Suhr J, Lynge E. Condom use to enhance regression of cervical intraepithelial neoplasia: study protocol for a randomized controlled trial. Trials. 2019;20(1):473. https://doi.org/10.1186/ s13063-019-3564-4.

\section{Publisher's Note}

Springer Nature remains neutral with regard to jurisdictional claims in published maps and institutional affiliations.
Ready to submit your research? Choose BMC and benefit from:

- fast, convenient online submission

- thorough peer review by experienced researchers in your field

- rapid publication on acceptance

- support for research data, including large and complex data types

- gold Open Access which fosters wider collaboration and increased citations

- maximum visibility for your research: over $100 \mathrm{M}$ website views per year

At BMC, research is always in progress.

Learn more biomedcentral.com/submissions 